\title{
NATUREZA, MEIO AMBEINTE E A TEORIA GERAL DOS SISTEMAS Bases Ambientais, Econômicas e Jurídicas
}

\author{
J. FALCAO SOBRINHO ${ }^{1}$, A. P. M. SOUZA ${ }^{2}$; I. L. C. FALCÃO ${ }^{3}$ e I. L. C. FALCAO ${ }^{3}$. \\ ${ }^{1}$ Universidade Estadual Vale do Acaraú/UVA, Sobral/Ceará, ${ }^{2}$ Faculdade Luciano Feijão, \\ ${ }^{3}$ Centro Universitário 7 de Setembro UNI7 \\ falcaosobral@gmail.com
}

Submetido 04/10/2015 - Aceito em 04/12/2017

DOI: $10.15628 /$ holos.2016.3485

\section{RESUMO}

Este ensaio objetiva enfatizar a natureza, em seus aspectos naturais e econômicos, associando-os às questões ambientais e jurídicas. Adota-se, como fins metodológicos, uma análise histórica, permeando-se, ainda, diversas ciências, quais sejam as Ciências Humanas, no contexto da Geografia; as Ciências Ambientais, coadunada à Biologia; e, por fim, as Ciências Sociais Aplicadas, aliadas à Economia e ao Direito. Fez-se necessário adotar uma base teórica e metodológica que, permitisse refletir sobre a natureza e a economia, agregando-se o Direito para exercer a equidade desta relação. A partir dessa conjuntura, recorreu-se à investigação, por intermédio da Teoria Geral dos Sistemas, a qual revelou diversas prerrogativas sobre uma mesma metodologia, bem como as suas conveniências, no contexto da sua aplicabilidade.

PALAVRAS-CHAVE: Natureza, Ciências Ambientais, Ciências Sociais, Teoria Geral dos Sistemas.

\section{NATURE, AMBEINTE MEDIUM AND A GENERAL THEORY OF SYSTEMS Environmental Foundation, Economic and Legal}

\begin{abstract}
This essay aims to emphasize nature in its natural and economic aspects by associating them with environmental and legal issues. As a methodological purpose, a historical analysis is adopted, and various sciences, such as the Human Sciences, in the context of Geography, are also permeated; the Environmental Sciences, in line with Biology; and, finally, the Applied Social Sciences, allied to Economics and Law. It was necessary to adopt a
\end{abstract}

theoretical and methodological basis that would allow to reflect on nature and the economy, adding the right to exercise the equity of this relationship. From this juncture, the investigation was used, through the General Theory of Systems, which revealed several prerogatives on the same methodology, as well as its conveniences, in the context of its applicability.

KEYWORDS: Nature, Environmental Sciences, Social Sciences, General Systems Theory. 


\section{INTRODUÇÃO}

O meio ambiente é constituído de elementos químicos, físicos e biológicos. Em uma abordagem das ciências da natureza, esse meio abrange as relações entre as bases físicas e naturais e, o homem. Desta forma, abordar-se sobre essa temática consiste, também, em se analisar a sua relação com o homem e a sociedade.

Registra-se que, é dos recursos naturais que se retiram os insumos necessários para a produção dos bens utilizados no consumo. Essa interdependência entre o homem e a natureza é essencial para a vida humana, no sentido de que, as tecnologias, por mais sofisticadas que sejam, têm, comumente, alguma parte essencial, retirada do meio ambiente.

É importante salientar que, independentemente da ciência, quando existem danos, na relação sociedade e natureza, origina-se um impacto ambiental. Desta feita, o impacto ambiental representaria uma situação adversa, causadora de graves danos ecológicos e sociais ao meio ambiente.

Não obstante, a Resolução $n$ o 1/86, do Conselho Nacional do Meio Ambiente (CONAMA), em seu art. 1ํ, qualifica o impacto ambiental como:

[...] qualquer alteração das propriedades físicas, químicas e biológicas do meio ambiente, causada por qualquer forma de matéria ou energia resultante das atividades humanas que, direta ou indiretamente, afetam:

I - a saúde, a segurança e o bem-estar da população;

II - as atividades sociais e econômicas;

III - a biota;

IV - as condições estéticas e sanitárias do meio ambiente;

$\mathrm{V}$ - a qualidade dos recursos ambientais.

Vale observar que, a Constituição Federal do Brasil (1988), reconheceu o direito ao meio ambiente, ecologicamente, equilibrado, como fundamental e indispensável. 0 art. 225 dessa Carta Magna colaciona que, "todos têm direito ao meio ambiente, ecologicamente, equilibrado, bem de uso comum do povo e essencial à sadia qualidade de vida, impondo-se ao Poder Público e à coletividade o dever de defendê-lo e preservá-lo para as presentes e futuras gerações".

A priori, este artigo respalda-se em um estudo da defesa do meio ambiente, notadamente, com a menção ao Princípio da Solidariedade Intergeracional. Desta feita, não somente o Poder Público possui um papel ativo, considerando-se que, a Constituição Federal do Brasil (1988) impôs, outrossim, à sociedade uma relevante função, no tocante à defesa e preservação do meio ambiente. Destarte, proteger o meio ambiente se trata, também, de 
proteger o cidadão, no presente e no futuro. Neste diapasão, Cavalcante e Mendes (2008, p. 34) lecionam que:

De fato, o ambiente é um bem jurídico essencial, corolário do próprio direito à vida, indispensável a uma condição de sobrevivência digna; além do que, transcende os limites da individualidade ou mesmo da coletividade, porquanto é direito e dever de todos e, ao mesmo tempo, de cada um, não sendo possível determinar e individualizar os seus destinatários.

Nota-se que, essa tensão existente entre o ambiente e o crescimento econômico demonstra a necessidade de se pensar em uma forma de se reduzir os efeitos do consumismo. Ademais, a maioria das pessoas possui uma percepção distorcida entre o ato de se viver bem e o consumismo, como afirma Condesso (2001, p. 22):

[...] Com efeito, com o apoio dos poderes políticos, o mundo, confundindo a qualidade de vida, o bem-estar, com o consumismo, com a abundância de bens industriais e o desperdício, desde há mais de um século, que tem vivido uma civilização industrial, geradora de efeitos ecologicamente depredadores, socialmente injustos e economicamente inviáveis e insustentáveis.

Diante dessa seara, o artigo em comento tem, como objetivo, embasar a natureza e o meio ambiente, em seus aspectos naturais e econômicos, associando-os às questões ambientais e jurídicas, apoiando-se, em uma base bibliográfica, com base metodológica, que perpassa por diversas ciências, qual seja a Teoria Geral dos Sistemas ${ }^{1}$.

\section{A NATUREZA DO MUNDO NATURAL E ECOLÓGICO}

De acordo com Falcão Sobrinho (1998), os elementos que constituem a natureza devem ser preservados nas suas diversas formas de recursos, tais como os solos, a vegetação, o relevo, os recursos hídricos, quando estiverem associados às ações do homem.

Desta maneira, e amparados pelo autor, há que se atentar à questão do usufruto da terra, como uma fonte de produção primordial e vital para a sobrevivência da espécie humana, esteando-se, nos recursos naturais, as condições básicas de sobrevivência. Nesta perspectiva, o estudo do impacto ambiental toma um enfoque do relacionamento homem/natureza, voltado à compreensão de como o ser natural, à medida que se tornou um ser social, pode se relacionar com a natureza, visando-se atender às suas necessidades, entre estas a produção de alimentos, sem cometer rupturas nos seus componentes.

1 A Teoria Geral dos Sistemas (TGS) foi desenvolvida pelo biólogo húngaro Ludwig Von Bertalanffy, em 1936. A perspectiva de sua aplicação é de caráter geral, de modo que possa ser aplicada aos fenômenos semelhantes que, ocorrem em uma diversidade de campos específicos de conhecimento. 
Nessa dimensão espacial abrangente, o termo impacto ambiental emerge, instituindo-se, como categoria de análise, a relação sociedade e natureza. Essa ampla vertente, em contrapartida, apresenta-se delimitada, no que tange a essa relação, permite que, o conhecimento científico se insira na discussão de impacto ambiental, de forma a se considerar a exploração da natureza pelo homem, no conjunto da sociedade, incluindo-se, como condicionante, o próprio recurso natural.

Seguindo esta linha de raciocínio, Falcão Sobrinho (1998) retrata que, as transformações na natureza já se sucediam antes mesmo da existência do homem, destacandose os terremotos, vulcões, abalos sísmicos e, as glaciações. Certifica-se que, estes fenômenos proporcionavam extermínios de várias formas de vida, animais e vegetais, tidos, em muitos episódios, como reguladores da natureza ou, dimensões evolutivas do planeta terra, não se tomando enfoque, nestes casos, de impacto ambiental.

No retrospecto evolutivo da espécie humana, a relação do homem para com a natureza sempre foi de exploração, mesmo que, em pequena escala. Conforme apontam os registros, as mudanças causadas pelo homem primitivo, na natureza, não são consideradas significativas, no que se refere aos impactos negativos, visto que a relação era de subsistência, em nível de colheita de frutos silvestres, caça, entre outros, bem como ocorreu na era inicial do intitulado "homem sedentário", reservando-se, a este, pequenas áreas para o plantio.

Verifica-se que, à medida que se aumenta a população, na face da terra, intensifica-se a relação de exploração dos recursos naturais, acrescendo-se o consumo de espécies vegetais e animais, bem como o consumo de água e, as diversas formas de produção, proporcionadas por instrumentos técnicos e químicos, o que convém se denominar de modernização.

Com decurso do tempo, o homem se direciona à outra abordagem do meio em que habita, tendo em vista que, o seu consumo, para suprir as necessidades biológicas diárias se perfaz, em uma produção de acúmulo, com a transformação, em escala, da matéria-prima, qual seja a vegetação, em artigos, tais como roupa, celulose, entre outros, para fins de produção de capital.

Analisa-se que, as novas formas de relacionamento com a natureza se pautam no ritmo do crescimento da população, porém a necessidade de subsistência tem, ainda, em um primeiro nível, o fato de se suprir a energia que, mobiliza a existência da espécie humana. No entanto, a produção de alimentos salta de uma escala local, para uma escala global, cuja finalidade primordial vem a ser a produção do capital. 
Diante desse contexto, as ações do homem relacionadas à produção de alimentos são fundamentais; e, o setor da agricultura é vital, contendo-se o solo, como base. À proporção que a população aumenta, torna-se necessária a produção de alimentos, em maior escala.

Novas formas de ocupações do uso do solo vêm sendo desencadeadas, ao longo do tempo, proporcionando-se mudanças, no meio físico natural. Tais mudanças evoluem em formas de pousio, conforme explica o trabalho sobre a evolução agrária, desenvolvido por Boserup (1997).

O pousio, como relata a autora, refere-se à forma gradativa de intervenção do homem no solo, para fins de produção e, o seu tempo de repouso, destacando-se: o cultivo com pousio longo ou florestal; o cultivo com pousio arbustivo; o cultivo em pousio curto; o cultivo anual; e, os cultivos múltiplos.

Esta evolução sistemática ocorre em virtude do aumento populacional, no decorrer do tempo, acompanhada de um processo modernizador de técnicas, implantadas, na produção de alimentos, do arado à máquina agrícola, do esterco natural ao fertilizante.

Neste contexto, sempre que se faz necessário o aumento da produção de alimentos, gera-se um maior impacto ambiental, pois as condições físicas, químicas e biológicas do meio físico são alteradas, em seus condicionamentos de nutrientes do solo, espécies vegetais, animais, em todo o meio físico natural, associadas às questões de êxodo rural. Trata-se de mudanças, intensificadas com a modernização implantada, no espaço agrário.

Conforme foi mencionada, a relação entre o homem e a natureza visava à subsistência. Nesta relação, a escala de utilização da terra era pequena, em se comparando com o ecossistema natural. Com a industrialização e consequente modernização, tal relação passou a ser de sociedade e natureza, culminando em uma escala que abrangeu uma maior área de atuação, acompanhada de técnicas, insumos agrícolas e desenvolvimento biológico, estes, não adequados ao meio natural. (FALCÃO SOBRINHO, 1998).

Este solo agrícola, que se torna objeto de uso, para atender às necessidades de subsistência do social, enquanto consumidor, e, às necessidades de acumulação de capital, com poucos produtores, reflete problemas ambientais, ocasionando-se uma sequência de impactos, a seguir expostos:

a) substituição de vegetação nativa por uma secundária, proporcionando-se o extermínio de espécies animais, predadoras e, essenciais ao equilíbrio do ambiente; 
b) interferência nos nutrientes do solo e, em sua estrutura, propiciando-se processos erosivos e, perda de capacidade produtiva;

c) uso de agrotóxicos que, contaminam o solo e o lençol freático; e,

d) a estrutura fundiária e o sistema de plantio afetam a população do campo, conferindo-se lugar às máquinas, favorecendo-se ao êxodo rural e à aglomeração, em centros urbanos.

Neste processo, o espaço do campo, destinado à produção de alimentos, para fins comerciais, apresenta, de forma sistêmica, uma evolução dos impactos ambientais, onde a relação sociedade/natureza se manifesta de forma dialética.

Por conseguinte, este quadro evolutivo da modernização não pode ser tratado apenas sob o aspecto de técnicas modernas e, a sua repercussão leva a uma dimensão ampla. Graziano Neto (1986) delibera que, ao mesmo tempo em que se insurge o progresso técnico, na agricultura, a organização da produção se modifica, o que condiz com as relações sociais e, não, técnicas de produção.

Durante muito tempo, entendia-se que, a preservação do meio ambiente impedia o crescimento econômico. Contudo, em uma nova visão sobre a fundamental relação entre o meio ambiente e o homem, constatou-se que, o desenvolvimento não deveria ser alcançado apenas com o crescimento da economia, visto que fatores coligados ao equilíbrio da natureza e à sua relação com o homem eram tidos como essenciais.

Vale argumentar que, o desenvolvimento, como objetivo fundamental da República Federativa do Brasil (BRASIL, art. 3ำ, inciso II, CF/88), puro e simples, outrora obtido mediante a destruição selvagem dos recursos naturais, concedeu espaço a um novo conceito, atingindo aspectos, desde o econômico ao social, cultural e sustentável.

O Código Florestal Brasileiro (BRASIL, 2012), em seu parágrafo único, assegura o desenvolvimento sustentável como objetivo, estabelecendo-se alguns princípios de observância obrigatória:

[...] I - afirmação do compromisso soberano do Brasil com a preservação das suas florestas e demais formas de vegetação nativa, bem como da biodiversidade, do solo, dos recursos hídricos e da integridade do sistema climático, para o bem-estar das gerações presentes e futuras;

II - reafirmação da importância da função estratégica da atividade agropecuária e do papel das florestas e demais formas de vegetação nativa na sustentabilidade, no 
crescimento econômico, na melhoria da qualidade de vida da população brasileira e na presença do País nos mercados nacional e internacional de alimentos e bioenergia;

III - ação governamental de proteção e uso sustentável de florestas, consagrando o compromisso do País com a compatibilização e harmonização entre o uso produtivo da terra e a preservação da água, do solo e da vegetação;

IV - responsabilidade comum da União, Estados, Distrito Federal e Municípios, em colaboração com a sociedade civil, na criação de políticas para a preservação e restauração da vegetação nativa e de suas funções ecológicas e sociais nas áreas urbanas e rurais;

V - fomento à pesquisa científica e tecnológica na busca da inovação para o uso sustentável do solo e da água, a recuperação e a preservação das florestas e demais formas de vegetação nativa;

VI - criação e mobilização de incentivos econômicos para fomentar a preservação e a recuperação da vegetação nativa e para promover o desenvolvimento de atividades produtivas sustentáveis.

Da percepção, a legislação expõe essa nova consolidação do conceito de desenvolvimento, conforme corroboram Vasconcelos e Marques (2012, p. 59):

Além da geração de riquezas e oportunidades, o desenvolvimento econômico tomou outra proporção, no sentido da necessidade da busca da melhoria na distribuição da renda e a melhoria da qualidade de vida, esta representada, entre outros fatores, por um melhor ambiente (preservado, conservado, recuperado e melhorado).

\section{A NATUREZA NO CONTEXTO ECONÔMICO}

Para muitos estudiosos, a atividade agropecuária pode ser considerada uma parte do que se convencionou designar de "setor primário" de uma economia. A outra parte simbolizava a atividade extrativa ou a mineração. A diferença básica entre esses divisores é óbvia: enquanto a agropecuária, composta da produção vegetal e da produção animal é reprodutiva, ratificando-se que, a sua capacidade de oferta é inesgotável, haja vista a sua vital dependência do trabalho humano, a atividade extrativa se infere como não reprodutível, visto que a obtenção de bens minerais encontra o seu limite, no estoque disponível, o qual é passível de exaustão.

De acordo com Ramos (2007), as suas atividades podem fornecer uma gama de bens, sejam estes representados por alimentos ou, insumos diversos. Pode-se destacar, nesse conjunto, o mercado de bens para alimentação humana, sobressaindo-se os que são matériasprimas industriais e, os que se destinam ao consumo animal.

Frisa-se que, a sazonalidade da produção agropecuária é outro aspecto que deve ser observado, em decorrência de que, o fluxo de bens não é contínuo, ao longo do ano, período de tempo em que se expressam, universalmente, quase todas as variáveis econômicas. Como a 
demanda, geralmente, é contínua, institui-se o problema do carregamento de estoques, advindo da distribuição do volume de oferta, no tempo para a sua adequação à demanda.

Esse panorama é válido, não apenas para produtos in natura e, engloba sérias implicações, no tocante à oscilação dos preços e, à comercialização de bens agropecuários. Essa combinação de sazonalidade produtiva e demanda contínua, no entanto, facilita os movimentos especulativos com os bens agropecuários.

Os diferentes ciclos de produção também são significativos. Há bens de ciclo curto, que compreendem menos de um ano, tais como as culturas temporárias e, a avicultura; e, há os de ciclo longo, tais como as culturas permanentes e, a pecuária bovina de corte. Neste último caso, há que se esclarecer que, mais importante do que o problema relacionado ao estoque é o da exigência de maior capital inicial, seja para a aquisição do ativo fixo, ou para formar o capital de trabalho, até que se iniciem os fluxos de produção.

Resta evidenciado que, nas atividades, tipicamente, industriais, também, existem diferentes ciclos de produção, mas estes tendem a ser contínuos e, não tão sujeitos à interferência de fatores naturais. Contudo, é notória a influência dos fatores climáticos.

A dispersão geográfica é outra característica da produção agropecuária. Deve-se recordar que, os bens agropecuários apresentam uma significativa diversidade quanto aos critérios de medidas e composição física: alguns são cotados em toneladas; outros, em caixas; e, ainda, uns terceiros, em arrobas, entre outros. É visível tal disparidade, quando se produz, em terras áridas, na superfície sertaneja, ou em maciços residuais úmidos, os quais possuem solos profundos e férteis.

Em síntese, pode-se afirmar que, as atividades agropecuárias estão sujeitas a dois tipos de riscos: o risco de produção, que é relacionado às condições naturais; e, o risco de preço, pertinente às condições econômicas. Compreende-se que, esses riscos têm uma forte interrelação. As perdas, decorrentes dessas condições, podem ser evitadas, em casos específicos, tal como a interrupção ou extensão do ciclo de produção, citando-se, como exemplo, a pecuária especulativa ou, com a formação de estoques, exemplificada através dos bens não perecíveis.

Consoante prenuncia Buainain (2007), uma das características marcantes da atividade agropecuária é a sazonalidade decorrente, existente, atualmente, em que se pesa o progresso tecnológico, da dependência de fatores climáticos, ambientais e dos ciclos biológicos das plantas e dos animais. O progresso tecnológico tem modificado a sazonalidade "natural", reduzindo-se o período de crescimento e maturação das espécies, desenvolvidas e adaptadas a ambientes 
diferentes daqueles originários, alterando-se as épocas de plantios, além da reprodução das condições climáticas e ambientais originais, destacando-se a plasticultura e a iluminação artificial.

Constata-se que, apesar dos enormes progressos, nesses campos, em maior ou menor grau, a atividade agropecuária permanece sazonal e, em grande escala, predominantemente, dependente dos fatores da natureza.

Seguindo esse ponto de vista, Buainain (2007) elucida que, essa dependência da natureza e, tal sazonalidade se reflete, em uma acentuada rigidez da produção agropecuária, seja para responder às mudanças, nas condições do mercado, ou para organizar os seus fluxos de produção e, de teor financeiro, de forma a se minimizar a necessidade de capital de giro, aproveitando-se, satisfatoriamente, das oportunidades ou, protegendo-se das flutuações dos mercados.

Enquanto que, na indústria, em geral, é possível se utilizar das receitas correntes para se garantir, no mínimo, parte dos gastos, na agricultura, despesas e receitas se realizam, em períodos distintos, de modo que, ao longo de vários meses o agricultor deve cobrir os seus gastos, por intermédio da preparação do solo, do plantio, da mão de obra, dos serviços, entre outros, a fim de que, após a colheita, seja realizada a receita, decorrente da venda de sua produção.

Cumpre asseverar que, esse mesmo paradigma acontece com os produtores de animais, particularmente, os de grande porte, criados em pastos e, não, em estábulos. Tal premissa significa que, a necessidade de capital de giro, na agricultura, é, proporcionalmente, mais elevada que na indústria. A partir desse parâmetro, admite-se a importância de políticas de crédito rural que, insiram a disposição dos produtores rurais, recursos, em condições compatíveis com as especificidades do setor atinente.

Entretanto, há que se perfilar a visão jurídica, no tocante ao assunto, quando se elucida a equidade ambiental, recorrendo-se ao tributo, em consonância com os ditames de Cavalcante e Mendes (2008):

Da forma como está previsto na Constituição da República, o Direito Tributário pode ser um excelente instrumento no desenvolvimento das questões pertinentes à proteção do meio ambiente, cujos elementos se refletem diretamente na organização estatal brasileira, assim como em qualquer outra do mundo. Seja no campo econômico, em que ocorre o crescimento e o fortalecimento do fenômeno globalizador do capital; na política, onde se observa um avanço do neoliberalismo sobre os Estados defensores do bem-estar social; ou ainda, na sociedade, a qual vem apresentando novos padrões de atuação, com a proliferação de entidades ecológicas não governamentais. 
Verifica-se que, tal citação se estende às explanações de Silva (2010), quando trata do assunto referente à "regulação". Para a autora, o termo traz consigo uma desmedida carga de debates doutrinários. A regulação estatal da economia é um conjunto de medidas legislativas, administrativas e convencionais, abstratas ou concretas, pelas quais o Estado, de maneira restritiva da liberdade privada ou, meramente, indutiva, determina, controla, ou influencia o comportamento dos agentes econômicos, evitando-se que, lesem os interesses sociais, definidos no marco da Constituição, orientando-os, em direções, socialmente, desejáveis.

\section{A NATUREZA NA ABORDAGEM JURÍDICA}

De acordo com Antunes (2006), sempre houve normas voltadas para a tutela da natureza. Tal proteção, comumente, constituía-se por normas de Direito Privado, que protegiam as relações de vizinhança ou, por normas de Direito Penal ou Administrativo que, sancionavam o mau uso dos elementos naturais ou a utilização destes, quando causavam prejuízos ou incômodos a terceiros.

Entretanto, a problemática suscitada pelos novos tempos demanda uma outra forma de se conceber a legislação de proteção ao meio ambiente. As antigas formas de tutela propiciadas pelo Direito Público ou pelo Direito Privado são insuficientes, para se responder a uma realidade, qualitativamente, diversa.

Nota-se que, esse fato pode ser observado nas obras de outros autores. Após a Independência do Brasil, autores, tais como José Bonifácio de Andrada e Silva ${ }^{2}$ e, Joaquim $\mathrm{Nabuco}^{3}$, preocuparam-se, entre outros ideais, com a defesa dos elementos da natureza. Porém, conforme destaca Milaré (2005), "nossa história, infelizmente, é de uma depredação ambiental impune. Na prática, somente eram punidos os delitos que atingissem a Coroa ou os interesses fundiários das classes dominantes".

Assim, durante a fase imperial e o início da República, a utilização indiscriminada dos recursos naturais não era, sistematicamente, tratada pelo ordenamento jurídico, e, a sua punição, quando existia, obedecia aos interesses, e, não, à efetiva proteção ambiental.

2 Estadista brasileiro conhecido como "o Patriarca da Independência.".

3 Foi um dos fundadores da Academia Brasileira de Letras. 
Ainda, segundo Milaré (2005), após a Proclamação da República, ocorrida em 15 de novembro de 1989 e, a edição do Código Civil de 1916 se insurge os primeiros diplomas legais, destinados, especificamente, à proteção da Natureza. No entanto, conforme destaca o autor, somente a partir da década de 1980 é que a legislação sobre a matéria passou a se desenvolver com sistematicidade e celeridade.

Silva (2010), ao tratar do direito econômico, abrange o direito ambiental, ressaltando ser este o direito, cujo titular não é, necessariamente, determinado. De fato, o destinatário deste direito "ambiental" engloba toda a humanidade, incluindo-se aqueles que, ainda, não estão aqui, preceito este consagrado ao princípio da responsabilidade entre gerações. Portanto, aqueles que, fazem-se presente, atualmente, não podem utilizar o meio ambiente, de forma a provocar a sua escassez para as gerações vindouras.

Milaré (2005) delineou quatro marcos legislativos, corroborando-se à mudança de mentalidade do legislador brasileiro, que foram:

a) Lei 6938/81, Lei da Política Nacional do Meio Ambiente, que instituiu o Sistema Nacional do Meio Ambiente (SISNAMA);

b) Lei $7347 / 85$, que disciplinou a Ação Civil Pública, principal instrumento processual para a proteção do meio ambiente;

c) Constituição de 1988, que consolidou a proteção ao ambiente ao destacar um capítulo inteiro para tratar do tema; e,

d) Lei 9605/98, Lei dos Crimes Ambientais que, tem, por mérito, sistematizar as sanções penais, oferecer uma lógica orgânica aos crimes ambientais e, inovar no ordenamento jurídico, com a inclusão da pessoa jurídica, como sujeito ativo, nos crimes ambientais.

Silva (2010) relata a Ordem Econômica, na Constituição de 1988:

O princípio da defesa do meio ambiente conforma a ordem econômica (mundo do ser),
informando substancialmente os princípios da garantia do desenvolvimento e do pleno
emprego. Além de objetivo, em si, é instrumento necessário - e indispensável - à
realização do fim desta ordem, o de assegurar a todos existência digna. Nutre também,
ademais, os ditames da justiça social. Todos têm direito ao meio ambiente
ecologicamente equilibrado, bem de uso comum do povo - diz o art. 225, caput, da
Constituição.

O desenvolvimento nacional que, cumpre realizar um dos objetivos da República Federativa do Brasil e, o pleno emprego que, pressupõem uma economia autossustentada, suficientemente, equilibrada, para permitir ao homem se reencontrar, como ser humano, e, não apenas como índice econômico. 
Silva (2010) aponta que, a proteção ao meio ambiente angariou reforço, em nível nacional, com a Constituição de 1988 que, instituiu três tipos de responsabilidade para o dano ecológico, independentes entre si: a administrativa; a criminal; e, a civil.

Entretanto, citado autor explicita que, essas três esferas de atuação, para a reparação ao dano ecológico, vêm se mostrando ineficazes, no tocante à proteção ao meio ambiente. Sem entrar no mérito da eficiência da atuação do Poder Público, nestas respectivas searas jurídicas, o que se esquivaria do escopo deste trabalho, estes instrumentos protetivos são insuficientes, mormente, porque lidam apenas com a reparação do dano ambiental, em que, a intervenção estatal só se dará depois de ter ocorrido a lesão ao meio ambiente.

Acrescenta-se, ainda, a preocupação com a natureza e o meio ambiente, em nível mundial, na busca de um desenvolvimento sustentável. Tal fato ocorreu com a Conferência Mundial, ECO-92, realizada na cidade do Rio de Janeiro, Brasil, caracterizada por tentar equilibrar e, conciliar o desenvolvimento socioeconômico, mediante proteção do meio ambiente. Desta feita, a ideia de progresso a todo custo é afastada, conferindo-se espaço para o respeito ao meio ambiente. O crescimento econômico é possível, desde que haja a preservação da natureza, e esse intuito é o ideal. (MACHADO, 2013, p. 73).

Estatui-se, portanto, que, devem-se juntar a prosperidade econômica e a proteção ao meio ambiente, em benefício das gerações, atual e futura. A título exemplificativo aponta-se à exploração racional, dos recursos naturais não renováveis, os quais devem ser consumidos, com cautela e, preservados para as próximas gerações, resguardando-se a natureza. (SIRVINKAS, 2015).

Por fim, a Comissão Mundial de Meio Ambiente e Desenvolvimento (World Commission on Environment and Development) definiu o desenvolvimento sustentável:

[...] é o desenvolvimento que atende às necessidades do presente, sem comprometer a capacidade de as futuras gerações atenderem às suas próprias necessidades. Em outras palavras, é o processo de transformação no qual a exploração dos recursos, as diretrizes de investimento, a orientação do desenvolvimento tecnológico e as mudanças institucionais sejam consistentes com as necessidades atuais e futuras. (BRUNDTLAND, 1987) 


\section{O PERCURSO DA ABORDAGEM SISTÊMICA NAS CIÊNCIAS NATURAIS E NAS CIÊNCIAS SOCIAIS APLICADAS}

A Teoria Geral de Sistemas, também, conhecida pela sigla T.G.S., originou-se através do biólogo alemão, Ludwig von Bertalanffy, publicada em vários trabalhos (1968, 1972, 1975, 1976).

Vale explanar que, a T.G.S. não busca solucionar problemas ou, tentar soluções práticas, mas produzir teorias e formulações conceituais que, possam criar condições de aplicação, na realidade empírica.

Diante dessa conceituação, os seus pressupostos básicos elencam que, existe uma nítida tendência para a integração, nas várias ciências naturais e sociais; a integração parece se direcionar, rumo a uma teoria dos sistemas; essa teoria de sistemas pode ser uma maneira abrangente de se estudar os campos não físicos do conhecimento científico, especialmente, as ciências sociais; tal teoria, ao desenvolver princípios unificadores que, atravessam, verticalmente, os universos particulares das diversas ciências envolvidas, aproxima-se do objetivo da unidade da ciência, o que pode se conduzir a uma integração indispensável da educação científica.

A importância da TGS é expressiva, tendo em vista a necessidade de se avaliar a organização, como um todo e, não somente em departamentos ou setores. O primordial consiste na identificação do maior número de variáveis possíveis, externas e internas, que, de alguma forma, influenciam todo o processo existente, na Organização. Outro fator, também, relevante é o feed-back que, deve existir no planejamento de todo o processo.

Christofoletti (1980) elabora uma sistematização do modelo estrutural e funcional da Teoria Geral dos Sistemas, argumentando-se que, o sistema é um conjunto de elementos e de suas inter-relações, dimensionando-se da seguinte forma:

a) sistemas isolados: não sofrem perda, nem recebem energia ou matéria; e,

b) sistemas não isolados: ocorre inter-relação com os elementos que compõem o sistema e o meio onde se encontram, podendo ser abertos ou fechados.

Aduz-se que, os sistemas abertos trocam matéria e energia entre si, como exemplo, uma bacia hidrográfica. Quanto aos sistemas fechados, estes trocam energia, mas não trocam matéria, tendo-se, como exemplo, o ciclo hidrológico. O importante é verificar que, a abordagem da Teoria Geral dos Sistemas foi influenciada pela natureza, a fim de se entender a sua autorregulação. 
Ademais, os conceitos fundamentais da Teoria Geral dos Sistemas são:

a) interação: ação recíproca que pode modificar o comportamento dos elementos que compõem o sistema;

b) totalidade: um sistema não é simplesmente a soma de elementos que o compõem, mas o todo, não se olvidando as suas partes;

c) organização: organização estrutural e funcional; e,

d) complexidade: o grau de complexidade dependerá do número de elementos que compõem o sistema, além do tipo, do número de inter-relações existentes entre estes e, da sua hierarquização.

No que tange aos elementos ou unidades dos sistemas, estes são constituídos por:

a) relações: as unidades estão inter-relacionadas, uma dependendo da outra, apresentando fluxos;

b) atributos: são qualidades que, caracterizam os elementos do sistema, auxiliando na descrição de comprimento, volume, área, composição e densidade dos fenômenos;

c) entrada (input): constituída por aquilo que o sistema recebe de energia para o seu funcionamento, visto que cada sistema é alimentado por diversos tipos de entrada;

d) saída (output): o que entra no sistema sofre transformações no interior dele; e,

e) realimentação (feedback): processo de controle para se manter o sistema em equilíbrio.

As características principais da estrutura de um sistema são:

a) tamanho: é definido conforme o número de unidades que compõem o sistema;

b) correlação: a correlação entre as variáveis do sistema estabelece o modo pelo qual elas se relacionam, em que a força indica o valor da intensidade, e, o sinal positivo ou negativo, a direção em que ocorre o relacionamento; e,

c) casualidade: a direção mostra qual variável é independente e, qual é dependente, sendo que, a variável dependente, que é controlada, sofrerá alterações somente quando a independente, que controla, se alterar.

Tal ordenamento natural favoreceu para que, a Teoria Geral dos Sistemas se impulsionasse, nas ciências naturais, principalmente, voltada à Ecologia. A partir dessa vertente, instituíram-se tipos de modelos, para se especificar a Teoria Geral dos Sistemas, os quais podem 
ser identificados como uma representação abstrata e simplificada da estrutura e função de algum sistema.

Tratando-se de outras ciências, no caso as Ciências Sociais Aplicadas, Moura et. al. (2009) estabelecem que, o movimento de positivação do Direito, em códigos legais, proporcionou para que, a ideia de sistematização ingressasse no campo das discussões jurídicas, tanto no campo legislativo, quanto no dogmático, posto que os códigos são tidos como um todo sistematizado de disposições legais sobre determinadas matérias, e, a ciência jurídica passa a ser compreendida como uma ordenação de conhecimentos ou conceitos acerca de certa disciplina pertinente.

De acordo com os autores, o pensamento sistemático, no campo jurídico, encontra a sua máxima formulação nos pensamentos de Canaries (2002). Da acepção, a ordenação é considerada a expressão de um estado de coisas, intrínseco e, racionalmente, apreendido, fundado na realidade; e, a e unidade consiste no fator de conexão e recondução do material apreendido a certos princípios fundamentais, capazes de evitar a dispersão de singularidades desconexas que, mantidas em uma relação de intercâmbio recíproco, aparecem como os elementos constitutivos do sistema de direito positivo e do sistema dogmático, voltados ambos à realização do valor fundamental da segurança jurídica.

De todas as formas, a dogmática jurídica se esteia como um sistema de ordenação conceitual, voltada à interpretação das disposições legais, de modo a se garantir uma aplicação racional, previsível, segura e harmônica, do Direito positivo ao caso concreto. Esta abordagem sistemática pretende produzir algumas vantagens, tais como:

a) facilitar o exame do caso concreto;

b) proporcionar uma aplicação, ao mesmo tempo uniforme, para os mesmos casos, e, diferenciada, para supostos diferentes do Direito;

c) simplificar e proporcionar ampla manuseabilidade do Direito, pelo operador; e,

d) oferecer um guia de elaboração e evolução do Direito positivo.

Vale salientar que, tais informações permitem refletir sobre o uso da natureza, ou dos recursos naturais, pautados no entendimento social, quando esta se apresentar, enquanto objeto de recurso. O caso específico do setor agropecuário envolve a Teoria Geral dos sistemas, em níveis diferenciados do ordenamento natural ou jurídico, priorizando-se receitas e baixos custos de despesas. 
A visão sistêmica é caracterizada pelo nível de agregação dada à atividade produtiva, não mais dividida entre setores agrícola, industrial e de serviços, perpassando-se esses setores, sendo caracterizada, também, pela análise de um produto específico e, pela inclusão das instituições, como uma variável não neutra. (MENDES et. al, 2008).

No contexto da Economia, Davis e Goldberg (1957 apud Mendes et. al, 2008) propagam que, na abordagem de Sistemas Agroindustriais (SAG) ou, Commodity System Approach (CSA), o sistema agroindustrial é entendido como um nexo de contratos e, apoia-se em uma cadeia produtiva, abrangendo-se segmentos outrora, inseridos, dentro e depois da porteira.

Ramos (2007), em contrapartida, alega que, a partir de meados da década de 1970, surgiram as primeiras formulações ou defesas de novas propostas analíticas para o setor agropecuário brasileiro. O primeiro pesquisador a mencioná-las foi Alberto Passos Guimarães, que utilizou o conceito de "complexo agroindustrial", inspirado, conforme as suas próprias determinações, em um trabalho de dois economistas norte-americanos, publicado, segundo o autor, naquele mesmo ano, mas que, em suma, teve o seu advento, em 1957.

Ramos (2007) considera, ainda, a inserção do conceito AGRIBUSINESS, como a:

soma total das operações de produção e distribuição de suprimentos agrícolas; as operações de produção nas unidades agrícolas; e o armazenamento, processamento e distribuição dos produtos agrícolas e itens produzidos com eles.

O referido autor introduz que, essas operações podem, assim, ser avaliadas, na visão sistêmica que, incorpora os seguintes elementos:

a) produção agropecuária propriamente dita: gêneros de cultivo e criação;

b) atividades de suporte ou de infraestrutura institucional: pesquisa, crédito, assistência técnica, treinamento de mão de obra, entre outros;

c) insumos extrassetoriais: fertilizantes, máquinas e implementos, sementes, defensivos, corretivos, entre outros;

d) canais de comercialização: estocagem, comércio atacadista e varejista, interno ou externo; e,

e) processamento dos produtos agropecuários: ramos industriais que utilizam matérias-primas agropecuárias.

Em se tratando de economia, poder-se-ia pensar que, a dificuldade de aplicação do princípio da divisão do trabalho, na agropecuária, constitui-se como um dos fatores explicativos das vantagens da produção conjunta de alguns bens agropecuários, em virtude de se obter um 
melhor aproveitamento de equipamentos e de mão de obra que, do contrário, permaneceriam, parcialmente, ociosos, durante o ano agrícola. Outras vantagens decorrem da não dependência do mercado ou do preço, geralmente, instável, de um único bem agropecuário e, dos efeitos das condições meteorológicas adversas, sobre uma única cultura.

Para o autor retromencionado, deve-se imaginar a abordagem sistêmica, no termo 'Regulação', imposto pela economia agrícola. Em curto prazo, a regulação se refere, especialmente, às intervenções do governo no nível de composição dos fluxos correntes de produção e demanda, com o objetivo de se "administrar os desequilíbrios" inerentes à economia de mercado, ou, de se procurar ajustar os fluxos aos objetivos políticos do governo.

Na hipótese da produção agropecuária, esses desequilíbrios são, no mínimo, em parte, qualificados pelas especificidades do setor, particularmente, das flutuações de produção e dos rendimentos físicos, associados, tanto aos fatores climáticos quanto à rigidez do processo produtivo que, dificulta os ajustes rápidos às mudanças, nas condições dos mercados relevantes. Ademais, tal observação não permite visualizar a autorregulação da natureza, ou seja, o seu estado de clímax.

Retomando-se à esfera jurídica, a compreensão da Teoria Geral dos Sistemas é, nitidamente, visualizada em Luhmann (2005, 2009), enfatizando-se que, o Direito integra os sistemas sociais e que, a sociedade agrega vários sistemas sociais. Para Ramos (2007), o Direito é um sistema que opera, de forma coadunada à auto-observação e, pela diferenciação entre sistema e meio, considerando-se, respectivamente, autorreferência e heterorreferência, em que o sistema se reproduz com as suas próprias estruturas. Essas discussões podem ser detalhadas em obras de autores, tais como, Pereira (2011), Palacios (2011), Moura et. al (2009) e Rocha et. al (2005).

No entanto, para Moura et. al (2009), o maior giro sistêmico, realizado por Luhmann, insere, na discussão, as contribuições da teoria da autoposiesis dos sistemas vivos, formulada pelos biólogos chilenos Maturana e Varela ${ }^{4}$, alcançando-se a uma inovadora versão da teoria geral dos sistemas, segundo a qual trata do próprio sistema que, simultaneamente, fechado e

4 De acordo com os autores "a organização autopoiética, como toda organização, pode ser obtida por muitas classes diferentes de componentes. No entanto, precisamos compreender que, no âmbito molecular da origem dos seres vivos terrestres, somente algumas espécies moleculares devem ter possuído as características que permitiram constituir unidades autopoiéticas, iniciando a história estrutural a que nós próprios pertencemos". (MATURANA e VARELA, 1995, p. 89). 
aberto, produz os seus elementos e as suas estruturas, proporcionando-se o denominado giro autopoiético.

Nesse sentido, Rocha et. al (2005) argumentam que, autopoiese advém da necessidade de se pensar naquilo que não poderia ser pensado, sendo um sistema que, não se configura como aberto, tampouco fechado, apresentando-se repetição e diferença.

Palacios $(2011)^{5}$ aduz que, a Teoria dos Sistemas Sociais de Luhmann (1998) altera a definição do sistema para o ambiente, onde a auto-organização passa a ter a autopoiese, introdução de sistemas que estão fechados em sua diferenciação, com os seus arredores e uma comunicação aberta, na sua totalidade. Destarte, não se deve confundir, integralmente, como uma oposição, mantendo-se o presente, como condição/relação: onde se está fechado, considerar-se uma base para o aberto, através de autopoiese condicionado. Emerge-se, desta proposta, um quadro conceptual para se analisar uma sociedade complexa.

Outra discussão decorre do paradigma da sociedade e do meio, conforme afere Luhmann (1990 apud PEREIRA, 2011):

Afirma ser a teoria dos sistemas a diferença entre sistema e meio. É o próprio sistema quem opera como observador aplicando a si mesmo a diferenciação entre sistema/ambiente, de modo indutivo e interno. O sistema se autodiferencia observando e determinando sua diferença com relação ao ambiente, daí este não ser menos importante do que aquele. (p. 89)

Da observação do resultado colacionado, infere-se que, tal posicionamento se torna fundamental, pois o sistema adotado por Luhmann deixa de ser operacional/positivista e, tornase dialético.

Merece enfoque a Teoria dos Sistemas, adotada por Luhmann, outrossim, quando for visualizada na conjuntura de várias ciências, tornando-se, assim, interativa. Diante deste cenário, há que se citar Moura et. al (2009, p. 7-9), delineando-se os quatro pilares metodológicos, na criação de sua base conceitual:

O primeiro deles é sua pretensão de universalidade, resultando numa verdadeira teoria geral do conhecimento que excede os limites da sociologia (alcançando, por exemplo, a política, a religião, a economia, o direito, etc.).

Em segundo lugar, a concepção de Luhmann parte de pressupostos multidisciplinares, envolvendo contribuições da física, da matemática, da cibernética, da neurociência, da biologia. Todos estes ingredientes são adicionados à teoria geral dos sistemas de

$5 \quad$ Para Palacios, "La teoría de sistemas sociales de Luhmann (1998) cambia la delimitación del sistema por el entorno, donde la autoorganización es sustituida por la autopoiesis, presentando sistemas que son cerrados en su diferenciación con su entorno y abierto en la comunicación de sus elementos". 
primeira ordem e culmina no surgimento de uma concepção sistêmica totalmente peculiar: "uma nova geração da teoria dos sistemas".

O terceiro pressuposto é a metodologia funcionalista adotada. LUHMANN propõe um estruturalismo funcionalista, onde deve ser radicalmente privilegiado o conceito dinâmico de função em face da noção de estrutura.

O último pressuposto diz respeito à utilidade dos paradoxos. Diferentemente da tradição do pensamento ocidental que considera o paradoxo como algo negativo, LUHMANN considera o paradoxo como algo positivo, construtivo que não leva a uma real contradição e à tautologia, mas à unidade conceitual, quando desparadoxizado pelo competente código binário. Cada sistema possui seu paradoxo específico (o do sistema econômico, por exemplo, é o paradoxo da escassez: cada acesso a bens escassos, que pretende diminuir sua escassez, a aumenta; o do sistema jurídico reside na positividade do Direito: este é válido apenas porque poderia ser diferente do que é). Mas dois deles possuem natureza geral, pertencentes a todos os sistemas. O primeiro é o paradoxo geral da unidade da diferença (unitas multiplex) entre sistema e ambiente: estes obtêm as respectivas unidades a partir da diferença marcada pelos seus limites. O segundo é o paradoxo do fechamento e abertura do sistema: o sistema só pode ser fechado porque é aberto.

\section{CONSIDERAÇÕES FINAIS}

É oportuno salientar que, a natureza é uma fonte de sustentação para a humanidade, tendo em vista que, por mais que os avanços tecnológicos sejam aprimorados e, permitam a sustentabilidade da produção de alimentos, têm-se, na base do solo, os elementos necessários a tais avanços. Necessário, ainda, se faz regular o modo de produção dos alimentos, da sustentabilidade e do equilíbrio dos elementos naturais.

Recorrendo-se à etimologia de Ecologia, palavra formada pelo termo 'oikos', que significa casa, e 'logos' (logia), que denota ciência, estudo. Portanto, de forma simples, ecologia significa a ciência que estuda a casa, o planeta Terra. Há, no entanto, outra ciência que possui uma formação vocabular semelhante, qual seja a Economia. Percebe-se que, diante da preocupação conceitual, afigura-se uma semelhança.

Observa-se que, na prática, não se conseguiu, ainda, um parâmetro que estabeleça um satisfatório zelo ecológico entre o mundo natural e o mundo social, em função do natural. Desta forma, verifica-se a necessidade de uma ciência, no caso, o Direito, para se promover este equilíbrio, através de um disciplinamento/ordenamento formal, em suas bases ecológicas e econômicas.

Nesse viés, o conceito de desenvolvimento torna-se alvo das discussões entre preservação e crescimento econômico. Não há antagonismo entre esses termos, ao contrário, a relação que a economia e o meio ambiente possuem é intrínseca à vida humana, no sentido de 
que, do meio ambiente se origina o local de onde se retiram os recursos essenciais à produção de bens que, promovem uma qualidade de vida eficaz.

Por fim, delibera-se o entendimento da natureza, por intermédio da Teoria Geral dos Sistemas que, quando tratada apenas pelos elementos naturais, se torna positivista e limitante da realidade atual. Portanto, inserir as ações da sociedade revela um juízo dialético, enaltecendose os debates entre as ciências, em busca da equidade entre natureza e sociedade.

\section{REFERÊNCIAS}

ANTUNES, Paulo de Bessa, 2006. Direito ambiental. 9. ed. Rio de Janeiro: Lúmen Júris.

BERTALANFFY, L. von, 1968. General System Theory. Foundations, development and applications. New York: George Braziler.

BERTALANFFY, L. von, 1975. Teoria geral dos sistemas. Petrópolis: Vozes.

BERTALANFFY, L. von, 1975. Perspectyvas en la teoría general de sistemas. Estudios científicofilosóficos. Madrid: Alianza Editorial.

BERTALANFFY, L. et. al., 1972. Tendencias en la teoría general de sistemas. Madrid: Alianza Editorial.

BERTALANFFY, L. et. al., 1976. Teoria dos Sistemas. Rio de Janeiro: Fundação Getúlio Vargas.

BOSERUP, Ester. (1997). Evolução agrária e pressão demográfica. São Paulo: Hucitec.

BRASIL. Constituição Federal., 1988. Constituição da República Federativa do Brasil: promulgada em 5 de outubro de 1988. Brasília: Senado, 1988. Disponível em: <http://www.planalto.gov.br/ccivil_03/Constituicao/Constituicao.htm>. Acesso em: 20 jun. 2017.

Lei $\mathrm{n}$ - 12.727, de 17 de outubro de 2012. Altera a Lei $\mathrm{n}^{\circ}$ 12.651, de 25 de maio de 2012, que dispõe sobre a proteção da vegetação nativa; altera as Leis $\mathrm{n}^{\text {os }} 6.938$, de 31 de agosto de 1981, 9.393, de 19 de dezembro de 1996, e 11.428, de 22 de dezembro de 2006; e revoga as Leis $\mathrm{n}^{\text {os }}$ 4.771, de 15 de setembro de 1965, e 7.754, de 14 de abril de 1989, a Medida Provisória n-2.166-67, de 24 de agosto de 2001, o item 22 do inciso II do art. 167 da Lei $\mathrm{n}^{\circ}$ 6.015, de 31 de dezembro de 1973, e o $\S 2^{\circ}$ do art. $4^{\circ}$ da Lei $\mathrm{n}^{\circ} 12.651$, de 25 de maio de 2012. Diário Oficial [da] República Federativa do Brasil, Poder Executivo, Brasília, DF, 18 out. 2012. Disponível em: <http://www.planalto.gov.br/ccivil_03/_ato20112014/2012/lei/l12727.htm>. Acesso em: 23/10/2014.

BRUNDTLAND, Gro Harlem, 1987. Our common future: the world commission on environment and development. Oxford: University Press. 
BUAINAIN, Antônio Márcio, 2007. Modelo e principais instrumentos de regulação setorial. In: RAMOS, Pedro et. al. (Orgs.). Dimensões do Agronegócio Brasileiro: políticas, instituições e perspectivas. Brasília: Ministério do Desenvolvimento Agrário/MDA.

CANARIS, Claus Wilhelm, 2002. Pensamento sistemático e conceito de sistema na ciência do direito. Tradução de A. Menezes Cordeiro. 3. ed. Lisboa: Fundação Calouste Gulbenkian.

CAVALCANTE, Denise Lucena e MENDES, Ana Stela Vieira, 2008. Constituição, direito tributário e meio ambiente. Revista Nomos, Fortaleza, Universidade Federal do Ceará.

CHRISTOFOLETTI, Antônio. (1980). Geomorfologia. $2^{\text {a } . ~ e d . ~ S a ̃ o ~ P a u l o: ~ E d g a r d ~ B l u c h e r . ~}$

CONDESSO, Fernando dos Reis. (2001). Direito do Ambiente. Coimbra: Almedina.

CONSELHO NACIONAL DO MEIO AMBIENTE. (1996). Brasília, DF: Ministério do Meio Ambiente.

FALCÃO SOBRINHO, José, 1998. A Modernização do Espaço Agrário. [S.I.]: Revista Essentia, p. 22 -34 .

GRAZIANO NETO, Francisco, 1986. Questão agrária e ecologia: crítica à moderna agricultura. São Paulo: Brasiliense.

LUHMANN, Niklas, 2005. A realidade dos meios de comunicação. Tradução de Ciro Marcondes Filho. Comunicação. São Paulo: Paulus.

LUHMANN, Niklas, 2009. Introdução à teoria dos sistemas. Tradução de Ana Cristina Arantes Nasser. Petrópolis: Vozes.

MACHADO, Paulo Affonso Leme, 2012. Direito Ambiental Brasileiro. 21 ed. São Paulo: Malheiros.

MATURANA, H. R.; VARELA, F, 1995. A árvore do conhecimento: as bases biológicas do entendimento humano. Campinas: Psy II.

MENDES, Krisley; FIGUEIREDO, Jeovan de Carvalho; MICHELS, Ido Luiz, 2008. A nova economia institucional e sua aplicação no estudo do agronegócio brasileiro. Revista de Economia e Agronegócio, [S.I.], v.6, n. 3, p. 309-242.

MILARÉ, Édis, 2005. Direito do ambiente: doutrina - jurisprudência - glossário. 4. ed. São Paulo: Revista dos Tribunais.

MOURA, Bruno de Oliveira; MACHADO, Fábio Guedes de Paula; CAETANO, Matheus Almeida, 2009. O Direito sob a perspectiva da teoria dos sistemas de Niklas Luhmann. Revista Sociologia Jurídica, [S.I.], n. 9, jul./dez. Disponível em https://sociologiajuridicadotnet.wordpress.com/o-direito-sob-a-perspectiva-da-teoria-dossistemas-de-niklas-luhmann/. Acessado em14/11/2014 
RAMOS, Pedro, 2007. Referencial teórico e analítico sobre a agropecuária brasileira. In: RAMOS, Pedro et. al. Dimensões do agronegócio brasileiro: políticas, instituições e perspectivas. Brasília: Ministério do Desenvolvimento Agrário/MDA.

RAMOS, Pedro et. al., 2007. Dimensões do agronegócio brasileiro: políticas, instituições e perspectivas. Brasília: Ministério do Desenvolvimento Agrário/MDA.

ROCHA, Leonel Severo; SCHWARTZ, Germano; CLAM, JEAN, 2005. Introdução à Teoria do Sistema autopoiético do Direito. Porto Alegre: Livraria do Advogado.

SILVA, Ana Paula Vasconcelos, 2010. O Direito ambiental e os novos paradigmas do Direito econômico: a ascensão do estado regulador. Rio de Janeiro: Revista da Faculdade de Direito da UERJ, p. 1 - 27.

SIRVINSKAS, Luís Paulo, 2015. Manual de Direito Ambiental. 13. ed. São Paulo: Saraiva.

PALACIOS, J. Milton J. Aragón. La teoría de sistemas autopoiéticos. Una breve introducción a una teoría radical de la sociedade, 2011. Revista Digital de Sociologia del Sistema Tecnocientifico, Espanha, v. 2, n. 1, p. 1-15.

PEREIRA, Geailson Soares, 2011. O Direito como sistema autopoiético. Revista CEJ, Brasília, ano 15 , n. 55, p. 86-92.

VASCONCELOS, Fernando Antônio de; MARQUES, Ana Paula, 2012. O desenvolvimento sustentável e os princípios ambientais na defesa do meio ambiente. João Pessoa: Prim@ Facie, p. 57 - 73. 